OPEN ACCESS

Edited by: Danijela Gasevic,

Monash University, Australia

Reviewed by:

Siti Munira Yasin,

MARA University of

Technology, Malaysia

Nicola Mucci

University of Florence, Italy

${ }^{*}$ Correspondence:

Lotta Dellve

lotta.dellve@gu.se

Specialty section:

This article was submitted to Occupational Health and Safety,

a section of the journal

Frontiers in Public Health

Received: 01 July 2020 Accepted: 27 November 2020 Published: 22 December 2020

Citation:

Skagert K and Dellve L (2020) Implementing Organizational WHP Into Practice: Obstructing Paradoxes in the Alignment and Distribution of

Empowerment.

Front. Public Health 8:579197. doi: 10.3389/fpubh.2020.579197

\section{Implementing Organizational WHP Into Practice: Obstructing Paradoxes in the Alignment and Distribution of Empowerment}

\author{
Katrin Skagert ${ }^{1}$ and Lotta Dellve ${ }^{2 \star}$ \\ ${ }^{1}$ Division Materials and Production, Research Institutes of Sweden (RISE), Gothenburg, Sweden, ${ }^{2}$ Department of Sociology \\ and Work Science, University of Gothenburg, Gothenburg, Sweden
}

Background: According to policy and theory, there is need for organizational workplace health promotion (WHP) to strengthen working conditions for all employees. However, earlier studies show it is hard to implement in practice. The aim was to critically analyze and identify interacting mechanisms and obstacles behind failures of organizational WHP projects from system perspectives.

Methods: A holistic case study was performed, to critically analyze data from an organizational WHP project approach at a public health care organization. The qualitative data was collected over 5 years and included interviews with key actors $(n=80)$, focus groups ( $n=59$ managers), structured observations ( $n=250$ hours), continuous field observations and documents $(n=180)$. Questionnaires to employees $(n=2,974)$ and managers ( $n=140$ ) was complementing the qualitative-driven mixed method approach.

Results: The analysis shows obstructing paradoxes of alignment and distribution of empowerment during the process of implementation into practice. The obstacles were interacting over system levels and were identified as: Governance by logics of distancing and detaching, No binding regulation of WHP, Separated responsibility of results, Narrow focus on delegated responsibilities, Store-fronting a strategic model, Keeping poor organizational preconditions and support for developments and Isolate WHP from other organizational developments.

Conclusions: The following premises can be formulated regarding successful organizational WHP programs. Consider (1) the uncertainty a distributed empowerment to all system levels may create; (2) the distributed impact to define the target and allow broader areas to be included in WHP; and (3) the integration into other development processes and not reducing the organizational WHP to the form of a project.

Keywords: alignment, structural empowerment, distributed leadership, system theory, implementation, health care organizational setting 


\section{INTRODUCTION}

Empirical studies and theoretical developments relating to successful workplace health promotion (WHP) in organizations highlight the importance of integrated focus on strengthening resources for health and developments at all organizational and work system levels (1-3). The integrated system approach of WHP, which increases empowerment of conditions supporting health and healthy work conditions, is suggested to be more sustainable, but there are limited studies on the more holistic approaches of WHP, such as organizational WHP (4). However, the implementation of such organizational WHP approaches can meet significant barriers between and within system levels $(5,6)$. Increased knowledge of the interaction of obstacles at each level and between levels can have importance for implementation of WHP projects, i.e., to better recognize and meet barriers to alignment and to distribute mandates for assessing, defining and conducting WHP activities. This study critically analyzes the implementation of a public organization's organizational approach of WHP that failed despite high ambitions. The study contributes to development of WHP theory by highlighting the obstructing paradoxes of distributed influence and learning as a necessary condition for empowerment and managerialism as norm in accountable public organizations (7).

The workplace is one important setting for enhancing health and well-being $(8,9)$. Organizational WHP considers structural measures with the aim of improving health for all employees (10), e.g., through strengthening working conditions (5), influence and access to resources and support structures in organizations (structural empowerment) $(11,12)$. Such organizational approaches of WHP have been highlighted from many perspectives. Policies point to the more holistic, system approaches of WHP, i.e., how the work is organized and an employee's ability to influence at work $(13,14)$. Theories of WHP and organizational change imply the importance of not (only) focusing on the individual but also the system and organization. Also, empirical studies of outcomes have concluded that WHP is most effective and sustainable when organizational levels are approached; when preventive and promotive perspectives combined; and when improvement of health are all integrated with other organizational improvement processes [see e.g., (1517)]. Earlier studies have reviewed and identified the most important factors for improving workers' health (18-22), and the evidence-based knowledge is quite robust. However, the significant interactions over and between individual, group, and organizational factors are less known. Some studies show a stronger magnitude of risks/resources for the interacting factors than for the single factors $(15,23)$. Therefore, WHP work based on the knowledge of how to handle interactions across organizational levels is needed and crucial for sustainable developments of employee health. This is also supported by studies showing that managerial work based on actively bridging organizational levels to integrate perspectives have had more success in producing sustainable organizational developments (24-26). Consequently, broader organizational approaches of WHP interventions would generally have a stronger effect than a WHP intervention focusing on single targets. Likewise, WHP at several levels could have a stronger effect than those focusing on one system level.

Nevertheless, WHP interventions most often focus on individual behavioral change rather than workplace change (27-31) even when the identified core challenges are clearly related to organizational conditions (32). Thus, despite the theoretical developments of WHP and global policies, knowledge about effective measures and approaches to improve working conditions is still needed (33-36). This includes knowledge of the central obstructing mechanisms and driving forces that hinder implementation and sustainability of organizational WHP.

Sustainable improvements of work organizations are understood, from a system perspective, as the continuous interaction between dimensions of intentions and the handling of actors, embedded in social and cultural conditions $(37,38)$. A theoretical framework for organizational WHP based on system theory suggests possible conditions of importance for crafting WHP conditions at each system level and in between (2). The framework integrates the key multi-conditions for WHP sorted into system levels, as well as the managerial work and organizing practices for crafting and bridging WHP across systems and levels. Such system perspectives on WHP focus more holistic approaches of factors, conditions and contexts at different levels: At the workplace in the daily work (microlevel); within the rules, structures, norms, and values of the organization (meso-level); with regard to impacts from the wider organization and society (macro-level) and related to temporal aspects and developments that may start at one level but have implications for all levels (chrono-level). Thus, implementation of organizational WHP requires distribution of empowerment, supporting influence and commitments (39) across systems. In connection to such system perspectives, alignment seems crucial for a stable common understanding of the organizations goals, purpose and vision regarding WHP (40). A functional alignment and distribution of empowerment is necessary (a) vertically so all the members of the organization know what and why a certain behavior is needed to contribute to the common goals of the organization, have mandates and can take actions, (b) horizontally between different work processes or units, and (c) diagonally, where superior executives and strategic management act as role models and synchronize and facilitate the desired actions at the lower hierarchical levels (the operative level) (41). Nevertheless, there is still a lack of knowledge of the mechanisms related to how conditions, drivers and obstacles interact between vertical, horizontal and diagonal levels.

This paper reports experiences from a case study of an implementation of organizational WHP at a medium-sized hospital in Sweden. The aim was to describe the implementation processes and critically analyze interacting mechanisms and obstacles behind failures of organizational WHP projects. Thus, the paper contributes to development of WHP theory by identifying the obstacles at each level involved in the proximal processes hindering distribution of empowerment over system levels. 


\section{MATERIALS AND METHODS}

\section{Study Design}

To analyze global characteristics of a program, the studydesign was a holistic case study approach (42). Case study design is recommended when (1) the aim is to understand complex interrelations between the phenomena studied [i.e., the implementation of and organizational WHP and their context (43)]; (2) the research ambition is to analyze 'thick' descriptions that represent different perspectives and (3) the researcher has little control over studied events but is interested in naturally occurring variability (44). The case was an implementation project of organizational WHP at a medium-sized hospital in Sweden. The study spans 5 years. Each phase of the implementation (the planning, active and integrated phase) (1), as well as the critical analyses of interacting obstacles, were primarily based on qualitative analyses of data from interviews, observations and documents, and supported by quantitative analysis of questionnaires. Thus, the major theoretical drive was inductive, i.e., a qualitative-driven mixed-method approach (45). The study was approved by the Regional Ethical Review Board (Dnr 433-10).

\section{Study Setting and the Studied Case}

The study took place in Sweden, where occupational health and safety management has been legislated since the late 1800's. The Swedish Work Environment Act (1977:1160) aims to prevent ill-health and accidents at work and achieve a good work environment. The labor market in Sweden has a long tradition of cooperation between employers and employees (i.e., union representatives) and this is also stipulated both in the work environment law and collective labor agreements. Although the workplace is often highlighted as an important arena for enhancing health and well-being, there is no binding regulation regarding workplace health promotion. There are, however, regulations that have shaped, constrained, and/or strengthened the occupational health and safety management, aiming to prevent ill-health rather than promote health.

The initiative for WHP was taken by the county council (macro-level). A steering board of union and employer representatives at the top level decided to take a further step toward putting workplace health promotion into practice. They identified a hospital as a preferred organization for such an implementation initiative and also had initial contact with the research group to study the implementation process. The studied organization (meso-level) was a middle-sized public hospital where process management and continuous improvement of processes had been going on for several years when this study started. The hospital had acute and planned care (including psychiatric care), a total of 800 beds and $\sim 4,500$ employees ( $82 \%$ women and $18 \%$ men). The hospital management teams' ambition was to implement workplace health promotion, with an organizational approach, and organized an implementation project for this purpose.

\section{Data Collection}

The holistic case study used a qualitative-driven mixed method approach for data-collection. For the purpose of the study, the qualitative data from interviews, focus groups, documents and notes from observation was the main source of data. Data from structured observation and questionnaires was complementing to provide broader descriptions and general views of and conditions for organizational WHP. The materials included in the holistic case study are described below:

Documents From year one (Y1) to year three (Y3), the implementation process was followed in the hospital's WHP process plans, management protocols, interviews and field notes. Data collection included all meeting protocols from the hospital top management ( $n=60, \sim 250$ pages) and from the three clinical divisions into which the care was organized $(n=120$, $\sim 350$ pages).

Individual interviews In-depth interviews were conducted (Y1-Y3) with key functions in the implementation process $(n=5)$ and line managers $(n=12)$. The interviews focused the implementation processes and important interacting conditions. The interviews were taped and additional notes were made. In order to better understand governance approaches, county council politicians ( $n=45$, Y1 and Y5) and key functions for organizational developments $(n=18)$ were interviewed about strategies to support improvements in hospital organizations. The majority of the interviews were transcribed; with the remainder careful notes were taken.

Focus-groups All first- and second-line managers and a strategic sample of employees from different professions and wards were invited to focus-group interviews, to discuss working conditions, their WHP approaches and the organizational WHP program. Altogether 59 managers participated in nine focus groups (Y1) and 68 employees participated in 12 focus groups (Y3). All focus-groups were transcribed.

Observations were made of work-place meetings $(n=9$, Y2-Y3) and top-management meeting ( $n=7$, Y2-Y3). For the purpose of the study, continuous field notes were also taken from ongoing contacts on site with managers at different levels and key-functions for implementation (Y1-Y5). Additionally, the continuous contact through e-mails, meetings and phone with leaders of the WHP project (about 3-12 contacts per month, Y1-Y3) was also used as data. Field notes and theoretical memos were written throughout the research process.

Structured observations In order to further assess signs of implementation in practice, 12 randomly selected firstline managers were shadowed regarding their work and time allocated to development work and other tasks, contacts and places of work. The observations were directly coded through a computerized structured observation scheme. Thus, the time used for each activity was observed by a researcher and directly registered using a computer program (46).

Questionnaires All first line managers were invited to answer a questionnaire, distributed through emails $(n=140$, response rate $75 \%, \mathrm{Y} 2)$. The responding managers $(n=105)$ mean age were 49 $(\mathrm{md}=51$, range $25-63$ years of age). Most $(85 \%, n=89)$ worked full-time as managers, other part of their working-time. The 
following variables were analyzed for the purpose of the present study: leadership approaches and support through superior manager (47). All employees were also invited to answer a questionnaire ( $n=2,974, \mathrm{Y} 3$, response rate $65 \%)$. For the purpose of the study, items of improvement work, improvement of quality of care, working conditions and efficiency were included in the analysis.

\section{Analysis}

The transcribed interviews, focus groups, field notes and documents (the qualitative raw data) were analyzed stepwise coded with manifest and latent codes in line with content analyses (48). First, descriptive qualitative analysis of the qualitative data were made sentence by sentence, to describe the chronological time and activities in the implementation project at the hospital (manifest coding of content). The second step in the qualitative analysis (latent coding) focused contextual factors and conditions of importance for the implementation process. The analytic latent coding was conducted based on system theory perspectives of organizational WHP and alignment over macro-, meso-, micro and chrono-levels. The result from the manifest coding resulted in descriptions of failures at several levels that were observed to be connected. Therefore, we chose to focus the latent coding on a critical perspective of the central obstacles for the development of organizational WHP, i.e., approaches, conditions and mechanisms that bridged system levels.

The complementing quantitative data were used to serve as examples and add additional perspectives to the qualitative analysis. Structured observations of managers were analyzed with descriptive statistics of time used on different activities. Descriptive analyses were conducted with questionnaire data. Prevalence ratios was also calculated, with data from employee questionnaire, for assessment of statistical differences of proportions (PR95CI).

\section{RESULTS}

The first result section describes the phases and central conditions of the implementation process. The second section presents the main categories from the critical analysis of proximal processes and key conditions for alignment and distribution over and within system levels.

\section{Case Description: Phases and Conditions for Implementation}

First, the implementation process in terms of the initiative for the project, the organizing and the activities are described in three partly overlapping phases: the planning phase, the active phase and the integrated (or not integrated) phase. Figure 1 and Table 1 lists the activities and to what extent they were performed.

The planning phase lasted about one and a half year (Y1Y2). The initiative to implement a WHP perspective in the organization came from a steering board with both union representatives and employers alongside the county council. One division in the county council was appointed to be a test arena for the implementation. A project organization was planned and the responsibility for the project was placed at the hospital's human resource (HR) unit by the hospital director. The project team consisted of a work environment strategist, two union representatives, one person who ordinarily was responsible for patient-related health promotion work, and an externally recruited project leader with a master's degree in public health. There was no project plan in place when the project leader was recruited, so her first task was to immediately start to write a project plan. It was an ambitious plan, based on a system theoretical holistic perspective and existing evidence on what distinguishes a WHP organization. The hospital's management team approved the project plan with goals and activities at the end of year one (the planning phase). The project plan had goals and activities on three (organizational, workplace and individual) levels. The overall goals were:

- Implement a WHP perspective in strategic management and governing documents

- Strengthen employee influence and participation in assessment of defining areas and resources to strengthen and open communication climate

- Enable health-promoting choices for the individual (employee)

According to the project plan, the active phase started at year two (Y2-Y3). When concrete activities were due to take place and be performed in the organization, several were rejected by the top management team with reference to economy or timing (see Table 1). Some of the activities seemed to disappear due to unclear communication and distribution of responsibility for the activities or mandates to take decisions. The top management's lack of responsibility and engagement was expressed in the interviews as an explanation for the uncertainty.

\begin{abstract}
"One of the most important, if not the most important, things when you run this type of change process is to have the highest management fully engaged and I do not feel that the project has that/... / but I think you have to decide in the hospital management whether you should seriously do this work at present or if you should actually put it on ice." - interview with person within the project team
\end{abstract}

Managers and employees also seemed to have different views on health. The project plan was based on the system theoretical view of health and activities mainly focused on organizational conditions, while the more traditional WHP focus on lifestyle activities was more widespread among operative managers and employees. In addition, at the organizational structural level, there were different views on whether the implementation was an HR-related process or an organizational improvement process. Altogether, this contributed to a lack of alignment and accountability of measures at different levels in the organization. The various views and expectations of the project collided, and the first project leader felt caught in the middle and resigned after 1.5 years. The next project leader was a HR specialist with more than 30 years of experience at the hospital. She also resigned after 1 year and was replaced with an externally recruited HR specialist who also resigned about a year later. 


\section{Case activities}

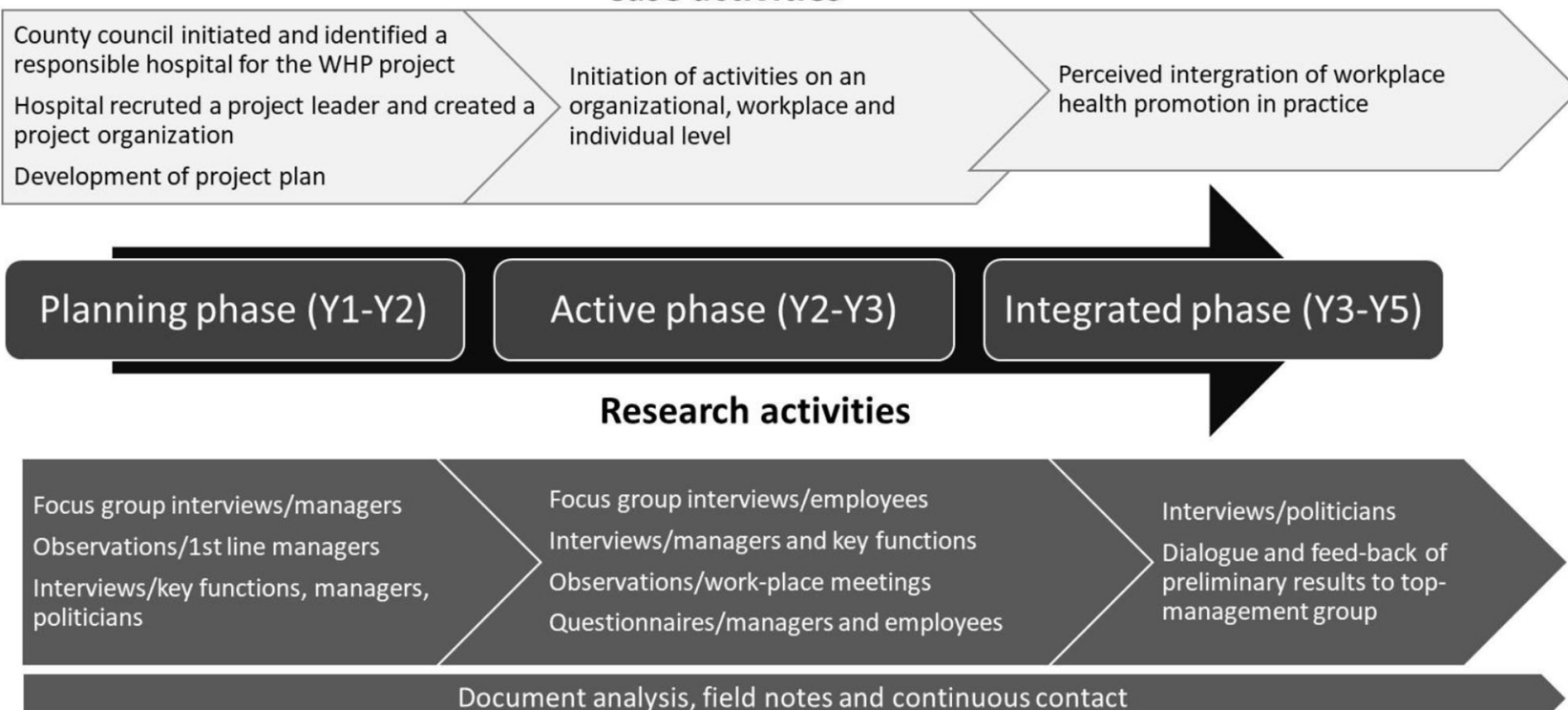

FIGURE 1 | Overall view of the case activities in the WHP project and the research activities.

According to the project plan, the integrated phase started at year three. To assess implications from the WHP project, all protocols from management teams at hospital- and clinical level were analyzed regarding their content. These protocols clearly indicated only one-way information from the WHP project team. Further, all initiatives for planned activities suggested by the WHP group or operative management to fulfill policy goals in practice were not approved by the hospital management group. For example, health coaches' desire to meet and share experiences and tools between organizational units was rejected. Despite the low activity regarding WHP, the law-regulated and prescribed health preventive measures seemed to function well at all levels. All agreed plans regarding prevention were followed by activities and follow-up regarding sick leave, work-related diseases and work-related injuries.

Second, conditions of importance for active work with WHP at operative levels were assessed. The managers, both first- and second-line, claimed that the support of communication flow between organizational levels and the support of empowerment and participation of subordinates were given the highest priority. Interviews, questionnaires and observations of the first-line managers showed their time conflicts related to allocation of time for the development work. The observation showed that work with developments happened during scheduled meetings (3\% of their total working time). Little time was also allocated to communication between superiors and subordinates. Firstline managers were on average communicating face-to-face with their own manager for $0.5 \%$ of their total working time and $10 \%$ met their manager every day. Most of the time (67\%), first-line managers were working at their office alone. Most of their time was allocated to administration or staffing challenges to solve immediate problems in the clinical work (Figure 2). The majority (87\%) of the first line managers assesses, through the questionnaire, that their leadership approach could be characterized as participative. And, that they gave their employees opportunities to have influence over the development work at the unit. The majority (82\%) also rated that they often discussed challenges in improvement work with their own manager. However, only $12 \%$ met their own manager every day, to discuss challenges. One third (28\%) met their own manager a few times per week or month (32\%) and $23 \%$ even lesser.

Despite managers having little time for aligning the WHP program between strategic and operative levels, the improvement work at operative level was observed as having a high degree of dialogue, participation and influence between the employees at several units. At operative units working more actively with the improvement work, strengthened working conditions (PR95\% CI 1.32 [1.25-1.39]), and also improved quality of care (PR95\% CI 1.19 [1.15-1.22]) and efficiency (PR95\% CI 1.58 [1.501.67]) was observed compared to units working less active with improvement work (from analysis of employee questionnaires).

\section{Obstructing Paradoxes for Alignment of Organizational WHP and Distribution of Empowerment}

Here, the result of the critical analysis of the lack of alignment and distribution of structural empowerment for WHP across organizational levels are presented. The approaches and decisions are contradicting and interacting (paradoxes) across systemlevels and thus obstructing alignment for organizational WHP and distribution of empowerment. The key obstacles are placed on the system level where they were based (Table 2). 
TABLE 1 | Overall view of the implementation plan activities and the degree to which activities were performed.

\begin{tabular}{|c|c|}
\hline $\begin{array}{l}\text { Planned activities on the } \\
\text { organizational level }\end{array}$ & Performed and/or implemented \\
\hline $\begin{array}{l}\text { Clarify and define the WHP } \\
\text { perspective in management } \\
\text { strategies and goals, governing } \\
\text { documents, and follow ups }\end{array}$ & $\begin{array}{l}\text { Done in the active phase but } \\
\text { disappeared in the (not) integrated phase }\end{array}$ \\
\hline $\begin{array}{l}\text { Integrate WHP competence } \\
\text { development with ordinary process } \\
\text { development }\end{array}$ & $\begin{array}{l}\text { Partly done in the active phase but } \\
\text { disappeared in the (not) integrated phase }\end{array}$ \\
\hline $\begin{array}{l}\text { Clarify cost and cons of workplace } \\
\text { health }\end{array}$ & Not done or integrated in any phase \\
\hline $\begin{array}{l}\text { Develop support and guidelines for } \\
\text { systematic workplace health and } \\
\text { work environment management }\end{array}$ & $\begin{array}{l}\text { Done in the active phase, no clear } \\
\text { integration }\end{array}$ \\
\hline Perform education in WHP leadership & Not done in any phase \\
\hline $\begin{array}{l}\text { Create a system to bring leaders and } \\
\text { employees up to date with stress } \\
\text { related health problems }\end{array}$ & Not done in any phase \\
\hline Activities on the workplace level & Performed and/or implemented \\
\hline $\begin{array}{l}\text { Development of a WHP dialog } \\
\text { material with different themes to be } \\
\text { distributed to all workplaces. The } \\
\text { objective was for it to be used at } \\
\text { workplace meetings in order to } \\
\text { assess areas and conditions to } \\
\text { strengthen }\end{array}$ & $\begin{array}{l}\text { Done and partly integrated in active } \\
\text { phase }\end{array}$ \\
\hline Activities on the individual level & Performed and/or implemented \\
\hline $\begin{array}{l}\text { Develop guidelines and health } \\
\text { promotion advice, for example to } \\
\text { night shift workers }\end{array}$ & Not done in active or integrated phase \\
\hline $\begin{array}{l}\text { Offer a wide range of wellness } \\
\text { benefits for the employees }\end{array}$ & Not done in active or integrated phase \\
\hline
\end{tabular}

\section{Macro-Level Obstacles}

The governance approaches of the studied county council (macro-level) were characterized by Logics of distancing and detaching. This implied deciding and providing preconditions but having a detached approach, with delegation, separation of responsibilities of results and a filtering of communication between organizational levels and functions. The governance approach was observed to bridge system levels; i.e., the logics of distancing and detaching were propagated as the valid management approach for public organizations. The macro-level conditions were also characterized by the non-binding regulation of WHP, which meant a lot of talking about the importance of organizational WHP was not followed by action.

\section{Meso-Level Obstacles}

Obstacles in hospital top-management (the meso-level) were connected to the macro-level governance. The following mesolevel obstacles were identified:

Focus on the clearly delegated responsibilities. The decision to implement an organizational WHP project with no demands for results was taken at the county council level. The hospital management team focused on their clearly regulated and delegated responsibilities. Reasons for these choices were the macro-level lack of regulation and demands of WHP, the hospital management teams' lack of genuine interest in WHP, and the lack of competence to handle conflicting organizational interests. Thus, their approach implied a management focus that reduced WHP to the regulated health prevention measures, which were applied and reasonably well-managed and negotiated at all organizational levels. At the same time, the organizational WHP was strategically vaguely managed by rhetoric and a storefronting policy model.

Structure and store-fronting a planned policy model. To fulfill the agreed WHP assignment, the management group decided a strategic plan and policy model for the WHP project based on best available evidence and with plans at meso- and micro system levels. This document was store-fronted upwards to county council levels to legitimize their accomplishment of the WHP project. This implied no further questioning from the county council level. Thereafter, a number of obstacles for the activity and integration phase were observed: (a) placing the project at the HR unit with a loose connection to the clinical core process and daily work practice, (b) dumping implementation on a group with little or no within-organizational power, (c) disenabling bureaucracy for distributing mandates, and (d) allowing complex systems that were hindering follow-ups.

An important obstacle was dumping the responsibility for implementation on a "satellite group" that was loosely anchored in the organization and had little power. The placement of WHP with a small group within the HR function served to isolate the WHP project from other organizational developments led by other organizational functions and spread over the hospital. The recruitment of a project leader with little earlier practical experience of hospital organizations was another approach to limit the influence of the group. Thus, the group and the project leader had difficulties in raising interest from clinical departments and supportive resources from staff functions. Instead, they further developed the written plans and handbooks despite their major difficulties in anchoring these at operative levels. Also at this level, the non-binding regulations regarding WHP meant that there was much talk and policy about intentions, interests and values but little action and prioritizing to fulfill those intentions.

The general governance approach of the county council, characterized by logics of distancing and detaching, acknowledged a detached approach of managing and organizing the WHP project, with delegation, separation of responsibilities and filtering of communication over organizational levels and functions. This seemed to hinder the operative managers, employees and professionals to have an overview of, engage with and exert influence over the WHP work. These approaches were in line with the governance of distancing and detaching, and can be characterized as measures of disenabling bureaucracy a designed organizational structure that decreases the influence and control outside the management group while also delegating responsibility for the accomplishment of the required operative tasks. The disenabling bureaucracy hindered empowerment conditions through formal organizational structures and social formations of communities. The disenabling bureaucracy was 


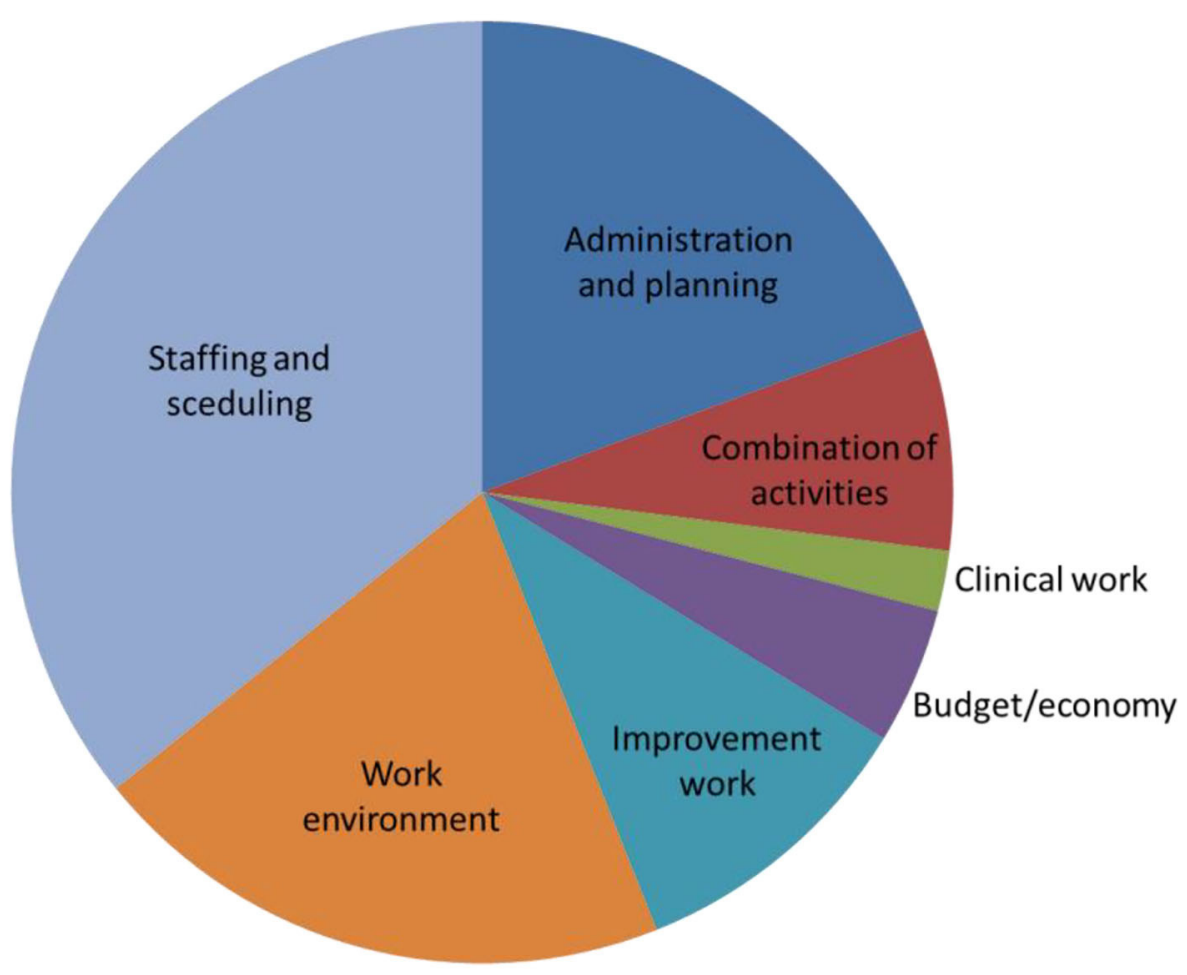

FIGURE 2 | Observed time-use among first-line managers.

observed as related to difficulties in fulfilling the goals of the strategic model in practice due to lack of mutual interest in the focused issue, economic resources, time and functional support. Further, the design of non-bridging independent systems of the organizational structure guaranteed the detached approach. Three main systems of register-based information were used in parallel and hindered follow-up regarding both accomplishment of responsibility and results. One collected information about economic issues, one about sick-leave and other vacancies and another about salary. None of these had the same picture of the organizational structure, including information about managers in charge that was shown on the hospital website. None of the systems covered all employees or followed the same organization structure.

\section{Micro-Level Obstacles}

The analyses identified hindering conditions in terms of poor organizational preconditions that prevented operative managers and other functions from participating in, engaging with and taking wider action regarding WHP. In this case the setting was characterized by high administrative and staffing load as well as dumped responsibilities without mandates for WHP at operative levels.

A heavy administrative and staffing load was placed on operative managers, for example through a large span of control, delegated responsibility of administrative duties, and no organizational support in staffing. The dumped (delegated) responsibilities for WHP at operative levels implied
TABLE 2 | Key obstacles for alignment and distribution of WHP across organizational levels.

\begin{tabular}{|c|c|c|c|}
\hline $\begin{array}{l}\text { Macro-level } \\
\text { obstacles }\end{array}$ & $\begin{array}{l}\text { Meso-level } \\
\text { obstacles }\end{array}$ & $\begin{array}{l}\text { Micro-level } \\
\text { obstacles }\end{array}$ & $\begin{array}{l}\text { Chrono-level } \\
\text { obstacles }\end{array}$ \\
\hline $\begin{array}{l}\text { No binding regulation } \\
\text { of WHP: talking but } \\
\text { little action } \\
\text { Governance by logics } \\
\text { of distancing and } \\
\text { detaching: separated } \\
\text { responsibility of results }\end{array}$ & $\begin{array}{l}\text { Focus clearly } \\
\text { delegated } \\
\text { responsibilities } \\
\text { - WHP reduced to } \\
\text { prevention } \\
\text { Creating and } \\
\text { store-fronting a } \\
\text { strategic model } \\
\text { - Disenabling } \\
\text { bureaucracy } \\
\text { - Dumping } \\
\text { implementation on } \\
\text { HR and a group with } \\
\text { little power } \\
\text { - Persisting complex } \\
\text { systems } \\
\text { hindering follow-up }\end{array}$ & $\begin{array}{l}\text { General poor } \\
\text { organizational } \\
\text { preconditions and } \\
\text { support for } \\
\text { development } \\
\text { - Administrative } \\
\text { and staffing load } \\
\text { on operative } \\
\text { managers } \\
\text { - Delegated and } \\
\text { detached } \\
\text { responsibilities for } \\
\text { WHP at operative } \\
\text { levels }\end{array}$ & $\begin{array}{l}\text { WHP activities } \\
\text { isolated from } \\
\text { development of } \\
\text { clinical } \\
\text { core processes } \\
\text { - Bad timing } \\
\text { Non-bridging } \\
\text { over levels } \\
\text { and perspectives } \\
\text { - Isolated good } \\
\text { examples }\end{array}$ \\
\hline
\end{tabular}

no organizational support or even interest from staff resources or the management team. The lack of support was expressed by operative managers and WHP coaches and also observed in protocols where no general organizational support for local or central WHP initiatives was accepted. Some of the managers also expressed poor competence in the WHP area and 
experienced little support from WHP coaches at operative level. Instead, employees with specific interest in wellness and fitness activities took responsibility for involving colleagues in such individual-focused health-promoting life-style activities.

\section{Chrono-Level Obstacles for Development}

The chrono-level encompasses the dimension of times, developments and trends of interests of WHP and work environment issues. Important conditions for developments are aligning the WHP activities over organizational levels and also integrating the perspectives of effectiveness, quality, and the work environment. Here, an important initial obstacle was to isolate the WHP activities from the development of clinical core processes by placing WHP within HR and isolated to a satellite group. Then, the timing of each WHP initiative was bad and the other obstacles observed and described above were successful in hindering the bridging and alignment of WHP activities and initiatives over organizational levels and units. This implied that there were isolated good examples of WHP that were not spread. Thus, the co-workers did not in general observe any WHP activities at the hospital.

\section{DISCUSSION}

This case study aimed to describe and critically analyze the implementation process of organizational WHP projects. The key result describes the activities in the planning, active and integrated (or not integrated) phases of a WHP project and the analysis shows obstructing paradoxes of alignment and distribution of empowerment during the process of implementation into practice. Thus, the approaches and decisions were contradicting and interacting (paradoxes) across system-levels and thus obstructing alignment for organizational WHP and distribution of empowerment. The important obstacles were identified as: Governance by logics of distancing and detaching, No binding regulation of WHP, Separated responsibility of results, Narrow focus on delegated responsibilities, Store-fronting a strategic model, Keeping poor organizational preconditions and support for developments and Isolate WHP from other organizational developments.

To sustain organizational change, the WHP project needs to be integrated into work practice (1) in all system levels of an organization (2). This was also basically the stated objective in the studied organization's WHP program. Yet it failed to be integrated. In line with Rojatz et al. (6), obstacles (or barriers) was found at contextual, organizational, intervention, implementer, and participant level in the different phases. The result of the analysis identified a number of key obstacles at all system levels that "curtailed" subordinates' mandates and structural empowerment as well as the possibility for followup within the organization. In the following text, we will try to highlight and problematize proximal processes of importance which can contribute to theoretical developments of frameworks for implementing organizational WHP.

Firstly, organizational WHP programs need to consider the uncertainty a true distributed empowerment to all system levels may create, and also the variety of defensive mechanisms that are mobilized to curtail insight and influence over system levels, in terms of: managerialism, bureaucratism (7) and separated systems for documentation and follow-up (49). These increase the gap of knowledge and practice (alignment) between the organization's strategic and operative levels and is mainly described in large public organizations. The macro-level strategies of county council politicians can be understood from the nature of their work, i.e., being based on a high degree of ambiguity, inherent conflicts and uncertainties which often result in avoidance and compromise in trying to balance multiple components and achieve different organizational goals. Nevertheless, the logics of governance seemed to have significant impact on the improvement work across organizational levels. Earlier studies have contrasted local logics of governance strategies (50) and showed higher work engagement among employees over time in more practice-oriented servant governance compared to the detached and upward-focused logics of governance identified in the studied county council (41). In the present study the passively controlling governance was related to top-management's active store-fronting of the program, which was absent within the organization. This is in line with Alvesson's (51) critical conceptualizing of the "triumphs of emptiness," when management ideas of grandiose change occur without actions at operative levels, and the identification by MacBeath et al. (7) of empty, controlling managerialism as the norm for organizational accountability in public organizations. Consequently, WHP programs would benefit from downward-focused servant leadership, with sincere interest in serving changes at floor through aligning influence and distribution of empowerment in a downward-directed manner to subordinates (26).

Secondly, organizational WHP programs need to consider the distributed impact to define the target and allow broader areas to be included in WHP. To have relevance, the assessment and prioritizing of WHP areas and conditions to strengthen must be defined at each system level. This requires a great deal of freedom from normative assumptions of what is "the right WHP." In the analyzed case, the county council conducted a problem analysis before the project started that was based on earlier research (52), and came to the conclusion that individual-oriented measures only reached a limited amount of the employees and most often those who already had a health-promoting life style. Thus, the project plan aimed to mainly improve organizational conditions for WHP. However, the problem analysis and resulting project plan was distributed within the organization and not further anchored to the local context that had other views of what was needed. Further, previous studies of organizational improvement of working conditions have highlighted the importance of actions being adapted to the problems that really exist and being based on a clear problem analysis that has a broader involvement (31, $35,53-55)$. Nevertheless, the concept of problem analysis might be ambiguous to use in a WHP context since it derives from pathogenic rather than salutogenic thinking. Experience showed, however, that when the strengthening activities really started, they often developed into more organizational WHP activities.

The current study is also an example of the contradictions regarding distribution of influence in defining organizational WHP activities: All suggested activities were rejected by 
top management. Thus, employees were "allowed" to make efforts to improve WHP as long as it didn't have impact on ordinary management and distribution of work. Thus, the case gives a description of poor alignment where the strategy, structure, and culture were not combined to create a "synergistic whole" (56). Instead, the dysfunctional interactions between and within the organization's levels became apparent. This can be a reason for poor sustainability of WHP (40) and highlights the need for continuous critical thinking of structural organizational power dimensions during an organizational WHP project. Theories of empowerment touch the "power" field and need to be complemented with theories of structural power relations involving both formal and informal power $(11,12)$. This may also yield results from WHP projects as structural empowerment is strongly correlated to health dimensions such as organizational commitment and psychological empowerment in public health care organizations (39). Thus, considering structural empowerment in organizational WHP program support increased effective workplace culture and organizational performance.

Thirdly, organizational WHP programs need to be integrated in other development processes (here: clinical improvements) and cannot be reduced to the form of a project. This WHP project had a well-defined plan according activities to all levels in the organization. However, a plan or strategic policy was not a guarantee of actual implementation of workplace health promotion into practice. The linear idea of implementing work health promotion through activities on different organizational levels might not be useful when it comes to this kind of "zone of complexity" (1). The obstacles for implementation of WHP in the present study were obvious at the meso-levels but related to the macro-level's detachment of responsibility for the results. The timing and lack of integration with the core business made it almost impossible for implementation at the meso- and micro levels. Nevertheless, when WHP was integrated with increased quality of care and effectiveness, there was significantly higher activity and improved working conditions.

The WHP plan included activities of creating a system to bring leaders and employees up to date with stress related health problems. Those activities did not seem to be implemented, still mandatory preventive measures (regulated by the Swedish Work Environment Act) seemed to function both at meso- and micro levels. There is robustly research of the job demandsresources model (57), where job demands can cause burnout and job resources (contribute to work engagement and well-being (58). Due to evidence, The Swedish Work Environment Act has been strengthened lately regarding the employers responsibility to prevent imbalance between job demands and resources. One practical implication of this might be that responsibility and authority for WHP will be closer to core business, and not to a strategic HR department which may increase the distance between WHP and the core business. These results are in line with the findings of Astnell et al. (59), who showed WHP activities increased when integrated with quality improvement work.

Dedicated engagement from top management is crucial for allocating resources in terms of time and competence (49). The allocation of time and priority was not the problem in this case from top-management's perspective. From the observations of operative managers, however, it was clear that little time was allocated to improvement work. Implementation of workplace health promotion into practice seems to have its own challenges in terms of taking abstract visions and strategies and putting them into practice (2). Instead, theory may contribute to a vicious circle between preconditions when implementing WHP and the effects of it. For example, this studied organization had a goal to increase employee influence but did not include participation in the planning phase. That, and the different views of health and health promotion, contributed to the gap between the strategic plan and the core care business.

\section{Methodological Considerations and Limitations of the Study}

The strength of the study is the 5-year long-term follow-up, the use of many measures for of data collection, from key actors representing many different views of and conditions for organizational WHP. The analysis would not come to the same conclusion if only one source of data were being used or the follow-up was shorter. The development of the project and the improvements were shaped and reshaped through contextual factors. The generalizability of the result is therefore not applicable and possible to replicate. Yet, the results may have transferability to similar contexts. Further, the results contribute to the theory frame of organizational WHP and points to the importance of considering broader methods for follow-up than merely chronological baseline-follow-up design. However, the broad descriptions of this article can also be seen as a limitation as results from in-depth analysis at individual and workplace levels was not included. Such in-depth analyses of individuals' and work-group perspectives are given in two thesis $(46,60)$. Another weakness is the single case-study design. An additional limitation, and at the same time a result of the study, is the lack of organizational follow-up data. One of the projects activities aimed to clarify costs and cons of workplace health. Data related to economic issues, quality of care and staff-related data such as short- and long-term sick-leave was collected in different systems and non-comparable organizational units. This makes it difficult for organizations to evaluate their own efforts to improve employee health.

\section{CONCLUSIONS}

This study shows that a well-performed plan for organizational WHP is no guarantee for actual implementation of WHP into practice. The linear idea of implementing WHP in activities on different organizational levels might not be useful when it comes to complex public organizations. Organizational WHP should rather be evolved through continuous improvements related to improvements of core business. The conscious and continuous efforts to improve how work is organized to enable employee influence in the organization should not be underestimated. The following premises can be formulated regarding sustainable organizational WHP programs. (1) Consider the uncertainty a distributed empowerment to all system levels may create; (2) Consider the distributed impact to define the target and allow 
broader areas to be included in WHP; and (3) Consider the integration into other development processes and do not reduce the organizational WHP to the form of a project.

\section{DATA AVAILABILITY STATEMENT}

Due to the ethical principals, the researchers are responsible for storing data for 10 years. The data supporting the conclusions of this article will be made available by the authors for as long as that.

\section{ETHICS STATEMENT}

The studies were reviewed and approved by The Regional Ethical Review Board at Sahlgrenska Academy, Dnr 433-10.

\section{REFERENCES}

1. Heward S, Hutchins C, Keleher H. Organizational change-key to capacity building and effective health promotion. Health Promotion Intl. (2007) 22:170-8. doi: 10.1093/heapro/dam011

2. Dellve L, Eriksson A. Health-promoting managerial work: A theoretical framework for a leadership program that supports knowledge and capability to craft sustainable work practices in daily practice and during organizational change. Societies. (2017) 7:12. doi: 10.3390/soc7020012

3. Andersen L, Fishwick D, Robinson E, Wiezer M, Mockallo Z, Grosjean V. Job satisfaction is more than a fruit basket, health checks and free exercise: Crosssectional study among 10,000 wage earners. Scand J Public Health. (2017) 45:476-84. doi: 10.1177/1403494817698891

4. Eriksson A, Orvik A, Strandmark M, Nordsteien A, Torp S. Management and leadership approaches to health promotion and sustainable workplaces: A scoping review. Societies. (2017) 7:14. doi: 10.3390/soc7020014

5. Bauer G, Davies JK, Pelikan J. The EUHPID Health Development model for the classification of public health indicators. Health Promotion Intl. (2006) 21:153-9. doi: 10.1093/heapro/dak002

6. Rojatz D, Merchant A, Nitsch M. Factors influencing workplace health promotion intervention: a qualitative systematic review. Health Promotion Intl. (2017) 32:831-9. doi: 10.1093/heapro/daw015

7. MacBeath J, Dempster N, Frost D, Johnson G, Swaffield S. Strengthening the Connections Between Leadership and Learning: Challenges to Policy, School and Classroom Practice. London: Routledge (2018).

8. Chu C, Breucker G, Harris N, Stitzel A, Gan XF, Gu XQ, et al. Health-promoting workplaces - international settings development. Health Promotion Intl. (2000) 15:155-67. doi: 10.1093/heapro/15.2.155

9. World Health Organization (WHO). The Ottawa Charter for Health Promotion. (1986). https://www.who.int/healthpromotion/conferences/ previous/ottawa/en/ (accessed June 26, 2020).

10. Giga SI, Noblet AJ, Faragher B, Cooper CL. The UK perspective: a review of research on organisational stress management interventions. Aust Psychol. (2003) 38:158-64. doi: 10.1080/00050060310001707167

11. Kanter RM. Men and Women of the Corporation. New York, NY: Basic books (2008)

12. Spreitzer GM. Taking stock: a review of more than twenty years of research on empowerment at work. In: Barling J, Cooper CL, editor. Handbook of Organizational Behavior, vol, 1. Thousand Oaks, CA: Sage (2008). p. 54-72. doi: 10.4135/9781849200448.n4

13. World Health Organization (WHO). Good Practice in Occupational Health Services - A contribution to Workplace Health. (2002). Available online at: https://www.euro.who.int/_data/assets/pdf_file/0007/115486/E77650.pdf (accessed June 26, 2020).

14. European Network for Workplace Health Promotion (ENWHP). Luxembourg Declaration on Workplace Health Promotion in European Union. (2007). Available online at: https://www.enwhp.org/resources/toolip/doc/2018/04/24/ luxembourg_declaration.pdf (accessed June 26, 2020).
The participants provided their written informed consent to participate in this study.

\section{AUTHOR CONTRIBUTIONS}

KS and LD truly collaborated in design of the work, data collection, data analysis and interpretation, drafting the article, critical revision of the article, and final approval of the version to be published.

\section{ACKNOWLEDGMENTS}

The authors thank Afa Insurance for financial support, E. T and C. B for data collection, and the participating politicians, managers and employees for sharing their time and knowledge.

15. Dellve L, Skagert K, Vilhelmsson R. Leadership in workplace health promotion projects: 1- and 2-year effect on long-term work attendance. Eur J Public Health. (2007) 17:471-6. doi: 10.1093/eurpub/ckm004

16. Shain M, Kramer DM. Health promotion in the workplace: framing the concept, reviewing the evidence. Occupat Environ Med. (2004) 61:643-8. doi: 10.1136/oem.2004.013193

17. Bennett JB, Cook RF, Pelletier KR. Toward an integrated framework for comprehensive organizational wellness: concepts, practices, and research in workplace health promotion. In: Quick JC, Tetrick LE, editors. Handbook of Occupational Health Psychology. Washington, DC: American Psychological Association. (2003). p. 69-95.

18. Lindberg P, Vingård E. Indicators of healthy work environments - a systematic review. Work. (2012) 41:3032-8. doi: 10.3233/WOR-2012-0560-3032

19. Nieuwenhuijsen K, Bruinvels D, Frings-Dresen M. Psychosocial work environment and stress-related disorders, a systematic review. Occup Med. (2010) 60:277-86. doi: 10.1093/occmed/kqq081

20. González R, Cockburn W, Irastorza X, Houtman I, Bakhuys Roozeboom M. European Survey of Enterprises on New and Emerging Risks Managing Safety and Health at Work; European Agency for Safety and Health at Work. Luxembourg: Publications Office of the European Union (2010).

21. Kelloway K, Teed M, Kelley E. The psychosocial environment: Towards an agenda for research. Int J Workplace Health Manag. (2008) 1:50-64. doi: $10.1108 / 17538350810865596$

22. Schütte S, Chastang JF, Malard L, Parent-Thirion A, Vermeylen G, Niedhammer I. Psychosocial working conditions and psychological wellbeing among employees in 34 European countries. Int Arch Occup Environ Health. (2014) 87:897-907. doi: 10.1007/s00420-014-0930-0

23. Holmgren K, Hensing G, Dellve L. The association between poor organizational climate and high work commitments, and sickness absence in a general population of women and men. J Occup Environ Med. (2010) 52:1179-85. doi: 10.1097/JOM.0b013e3181fc5cla

24. Dellve L, Wikström E. Managing complex workplace stress in health care organisations: Leaders' perceived legitimacy conflicts. J Nurs Management. (2009) 17:931-41. doi: 10.1111/j.1365-2834.2009. 00996.x

25. Wikström E, Dellve L. Contemporary leadership in healthcare organizations: fragmented or concurrent leadership and desired support. J Health Organ Manag. (2009) 23:411-28. doi: 10.1108/14777260910979308

26. Gunnarsdóttir S, Edwards K, Dellve L. Improving health care organizations through servant leadership. in practicing servant leadership. In: van Dierendonck D, Patterson K, editors. Developments in implementation. Cham: Palgrave Macmillan) (2018). p. 249-73. doi: 10.1007/978-3-319-75644-8_14

27. Torp S, Eklund L, Thorpenbergs S. Research on workplace health promotion in the Nordic countries: a literature review, 1986-2008. Global Health Promotion. (2011) 18:15-22. doi: 10.1177/1757975911412401

28. Torp S, Kokko S, Ringsberg KC, Vinje HF. Is workplace health promotion research inte the Nordic countries really on the right track? Scand J Public Health. (2014) 42:74-81. doi: 10.1177/1403494814545106 
29. Proper KI, van Oostrom SH. The effectiveness of workplace health promotion interventions on physical and mental health outcomes - a systematic review of reviews. Scand J Work, Environ Health. (2019) 45:546-59. doi: $10.5271 /$ sjweh.3833

30. Montano D, Hoven H, Siegrist J. A meta-analysis of health effects of randomized controlled worksite interventions: does social stratification matter? Scand J Work Environ Health. (2014) 40:230-4. doi: $10.5271 /$ sjweh. 3412

31. Lamontagne AD, Keegel T, Louie AM, Ostry A, Landsbergis PA. A systematic review of the job-stress intervention evaluation literature, 1990-2005. Int J Occupat Environ Health. (2007) 13:268-80. doi: 10.1179/oeh.2007.13.3.268

32. Åkerström M, Severin J. Organisatoriska problem löses inte med hjälp av individåtgärder. [Organizational problems are not solved through individual actions]. Socialmed Tidskrift. (2020) 97:55-65.

33. Nielsen K, Randall R. Opening the black box: Presenting a model for evaluating organizational-level interventions. Euro J Work Organ Psychol. (2013) 22:601-17. doi: 10.1080/1359432X.2012.690556

34. Cox T, Karanika M, Griffiths A, Houdmont J. Evaluating organizational-level work stress interventions: beyond traditional methods. Work Stress. (2007) 21:348-62. doi: 10.1080/02678370701760757

35. Kompier MAJ, Cooper CL, Geurts SAE. A multiple case study approach to work stress prevention in Europe. Euro J Work Organ Psychol. (2000) 9:371-400. doi: 10.1080/135943200417975

36. Nielsen K, Randall R, Holten A-L, González ER. Conducting organizational-level occupational health interventions: What works? Work Stress. (2010) 24:234-59. doi: 10.1080/02678373.2010. 515393

37. Kira M, van Eijnatten FM. Socially sustainable work organizations: conceptual contributions and worldviews. Syst Res Behav. (2011) 28:418-21. doi: $10.1002 /$ sres. 1083

38. Biggs A, Brough P, Barbour JP. Enhancing work-related attitudes and work engagement: A quasi-experimental study of the impact of an organizational intervention. Int J Stress Manage. (2014) 21:43-68. doi: 10.1037/a0034508

39. Fragkos KC, Makrykosta P, Frangos CC. Structural empowerment is a strong predictor of organizational commitment in nurses: A systematic review and meta-analysis. J Adva Nursing. (2020) 76:939-62. doi: 10.1111/jan.14289

40. von Thiele Schwarz U, Hasson H. Alignment for achieving a healthy organization. In: Bauer GF, Jenny GJ, editors. Salutogenic Organizations and Change. Dordrecht: Springer (2013). p. 107-25.

41. Dellve L. Tillitsskapande styrningspraktiker? [Trust-building governance?] Socialmed Tidskrift. (2018) 95:298-310.

42. Yin RK. Designing case studies. In: Maruster L, Gijsenberg MJ, editors. Qualitative Research Methods. London: Sage (2003). p. 359-86.

43. Stake, R. E. (2000). "Case studies," in Handbook of Qualitative Research, 2nd Edn., eds N. K. Denzin, and Y. S. Lincoln (Thousand Oaks, CA: Sage Publications), 435-455.

44. Ragin CC, Becker HS, (Eds.). What Is a Case? Exploring the Foundations of Social Inquiry. Cambridge: Cambridge University Press (1992).

45. Morse JM, Niehaus L, Wolfe RR, Wilkins S. The role of the theoretical drive in maintaining validity in mixed-method research. Qual Res Psychol. (2006) 3:279-91. doi: 10.1177/1478088706070837

46. Tengelin E. Creating Proactive Boundary Awareness - Observations and Feedback on Lower Level Health Care Managers' Time Commitments and Stress. [Licentatiate thesis]. Gothenburg: University of Gothenburg (2012).
47. Eklöf M, Pousette A, Dellve L, Skagert K, Ahlborg G. Gothenburg Manager Stress Inventory (GMSI). ISM-Report $\mathrm{Nr}$ 7. Gothenburg: Institute of Stress Medicine (2010).

48. Graneheim UH, Lundman B. Qualitative content analysis in nursing research: concepts, procedures and measures to achieve trustworthiness. Nurse Education Today. (2004) 24:105-12. doi: 10.1016/j.nedt.2003.10.001

49. Andreasson J. Organizational Preconditions and Supportive Resources for Swedish Healthcare Managers: Factors that Contribute to or Counteract Changes [Doctoral Thesis], Stockholm: KTH Royal Institute of Technology (2018).

50. Kalkan A, Sandberg J, Garpenby P. Management by knowledge in practice - implementation of national healthcare guidelines in Sweden. Soc Policy Administ. (2015) 49:911-27. doi: 10.1111/spol.12102

51. Alvesson M. The Triumph of Emptiness: Consumption, Higher Education, and Work Organization. Oxford: OUP (2013).

52. Jonsdottir I, Börjesson M, Ahlborg GJr. Healthcare workers' participation in a healthy lifestyle-promotion project in western Sweden. BMC Pub Health. (2011) 11:448. doi: 10.1186/1471-2458-11-448

53. Hammer LB, Truxillo DM, Bodner T, et al. Exploration of the impact of organisational context on a workplace safety and health intervention. Work Stress. (2019) 33:192-210. doi: 10.1080/02678373.2018. 1496159

54. Nielsen K, Randall R. Assessing and addressing the fit of planned interventions to the organizational context. In: Karanika-Murray M, Biron C, editors. Derailed Organizational Interventions for Stress and WellBeing. Dordrecht: Springer (2015). p. 107-13. doi: 10.1007/978-94-0179867-9_12

55. McFillen JM, O’Neil DA, Balzer WK, Varney GH. Organizational diagnosis: an evidence-based approach. J Change Manage. (2013) 13:223-46. doi: 10.1080/14697017.2012.679290

56. Semler SW. Systematic agreement: A theory of organizational alignment. Human Res Dev Quart. (1997) 8:23-40. doi: 10.1002/hrdq.3920080105

57. Bakker AB, Demerouti E. The job demands-resources model: State of the art. J Manag Psychol. (2007) 22:309-28. doi: 10.1108/02683940710733115

58. Lesener T, Gusy B, Wolter C. The job demands resources model: a metaanalytic review of longitudinal studies. Work Stress. (2019) 33:76-103. doi: 10.1080/02678373.2018.1529065

59. Astnell S, von Thiele Schwarz U, Hasson H, Augustsson H, Stenfors-Hayes T. Integrating health promotion with quality improvement in a Swedish hospital. Health Promot Int. (2015) 31:495-504. doi: 10.1093/heapro/dav027

60. Bergman C. Critical Conditions for Co-Workership in Healthcare Organizations: A Workplace Health Promotion Perspective [thesis]. Gothenburg: University of Gothenburg (2018).

Conflict of Interest: The authors declare that the research was conducted in the absence of any commercial or financial relationships that could be construed as a potential conflict of interest.

Copyright (c) 2020 Skagert and Dellve. This is an open-access article distributed under the terms of the Creative Commons Attribution License (CC BY). The use, distribution or reproduction in other forums is permitted, provided the original author(s) and the copyright owner(s) are credited and that the original publication in this journal is cited, in accordance with accepted academic practice. No use, distribution or reproduction is permitted which does not comply with these terms. 